\title{
Lumbar posterolateral fusion with local bone graft plus bone extender compared with iliac crest bone graft: a systematic review
}

Authors Robert A McGuire1, Leslie E Pilcher², Joseph R Dettori²

Institutions 1 University of Mississippi Medical Center, Jackson, MS, USA

2 Spectrum Research Inc, Tacoma, WA, USA

\section{ABSTRACT}

Study design: Systematic review.

Study rationale and context: Bone graft from the iliac crest has been the gold standard in posterolateral spinal fusion procedures, but is associated with chronic pain at the harvest site. Bone graft harvested locally from the spine and combined with extenders may decrease the morbidity associated with iliac graft harvest, but questions remain on the success of this technique to achieve bone union.

Objectives: Compare the fusion rate, functional outcomes, and safety of local bone graft plus bone extender compared with iliac crest bone graft in posterolateral spinal fusion procedures.

Methods: A systematic review of the literature was undertaken for articles published through January 2011. Pubmed, Cochrane, National Guideline Clearinghouse Databases, and bibliographies of key articles were searched. Two independent reviewers studied the articles. Inclusion and exclusion criteria were set and each article was subject to a predefined quality-rating scheme.

Results: We identified three articles meeting our inclusion criteria. Fusion rates were high across studies, with no significant differences between treatment groups in fusion, functional outcomes, or quality of life. There were two deep infections $(5.3 \%)$ in one study among patients receiving local bone graft plus extender.

Conclusion: Local bone graft plus bone extender has similar fusion rates, functional outcomes, and patient quality-of-life scores as iliac crest bone graft in posterolateral spinal fusion procedures. Additional randomized trials with standardized methods of measuring fusion and functional outcomes are needed.

This systematic review was funded by AOSpine. 


\section{STUDY RATIONALE AND CONTEXT}

Fusion of the spine is often required when treating instability and deformity. Classically, bone graft from the iliac crest has been the gold standard used to achieve this fusion. Studies reveal chronic pain with this graft harvest to be as high as $31 \%$ [5]. Bone morphogenetic protein has been used to achieve fusion but also has associated complications and expense [6]. This study looks at the success of achieving bone union using bone graft harvested locally from the spine and combined with extenders to decrease the morbidity associated with iliac crest graft harvest.

\section{OBJECTIVES}

To compare the fusion rate, functional outcomes, and safety of local bone graft plus bone extender compared with iliac crest bone graft (ICBG) in posterolateral spinal fusion procedures.

\section{MATERIALS AND METHODS}

Study design: Systematic review.

\section{Sampling}

- Search: PubMed, Cochrane collaboration database, and National Guideline Clearinghouse databases; bibliographies of key articles.

- Dates searched: through January 2011.

Inclusion criteria: (1) posterolateral lumbar fusion comparing local bone graft plus bone extender with ICBG and (2) comparative studies with concurrent controls.

Exclusion criteria: (1) Bone extender used without local bone graft; (2) prior lumbar surgery; and (3) case-series.

Outcomes: fusion rate; functional status; quality of life (QoL); and complications.

Analysis: The proportion of patients achieving fusion was reported as the number of patients fused in each group divided by the total number of patients within the group. Functional and quality of life measures were recorded as mean score or mean percentage improvement compared with baseline. Overall strength of evidence was assessed using GRADE criteria.

Details about methods can be found in the web appendix at www.aospine.orglebsj

\section{RESULTS}

We identified three articles meeting inclusion criteria (Fig 1). The indication for surgery was degenerative disc disease, spondylolisthesis, spinal stenosis, or deformity (Table 1). All three studies were randomized controlled trials, level of evidence I to II [1-3].

Further details on the class of evidence rating for these studies can be found in the supplemental material at www.aospine.orglebsj.

\section{Fusion rate of local bone plus extender versus ICBG (Fig 2)}

- Fusion rates were high across studies, with fusion seen in $100 \%$ of patients treated with local bone plus extender and $100 \%$ of patients treated with ICBG. No significant differences in fusion rates were seen between treatment groups $[2,3]$.

- One study comparing decompression bone plus calcium sulfate pellets (OsteoSet ${ }^{\circledR}$ ) used on one side versus ICBG used on the other side found $88 \%$ of patients showed bone formation on the intervention side that was $75-100 \%$ of, equal to, or more than that on the control side at 12 months after fusion. Bone mass, as measured by comparing the posteroanterior $\mathrm{x}$-ray with the lateral $\mathrm{x}$-ray as reference, was $17.27 \mathrm{~cm}^{2}$ on the intervention side versus $17.25 \mathrm{~cm}^{2}$ on the control side [1].

- Two additional studies measuring fusion by agreement between independent observers based on Christensen' classification found reported fusion in all patients whether treated with local bone plus extender or ICBG $[2,3]$.

\section{Functional status and QoL outcomes (Fig 3)}

- Functional status and QoL scores (Japanese Orthopedic Association, Oswestry Disability Index, SF-36) improved in all patient groups across studies, but no significant differences were found between treatment groups [2,3].

\section{Complications}

- Two studies reported complication rates; of these, one study found no complications in either treatment group and one found complications in both treatment groups; see Table 2 [2, 3].

- Among patients treated with local bone plus extender, two had deep infections (5.3\%), and one had a superficial infection [3].

- Among patients treated with ICBG, one had a deep hematoma and a second had a screw breakage [3]. 
Fig 1 Results of literature search.

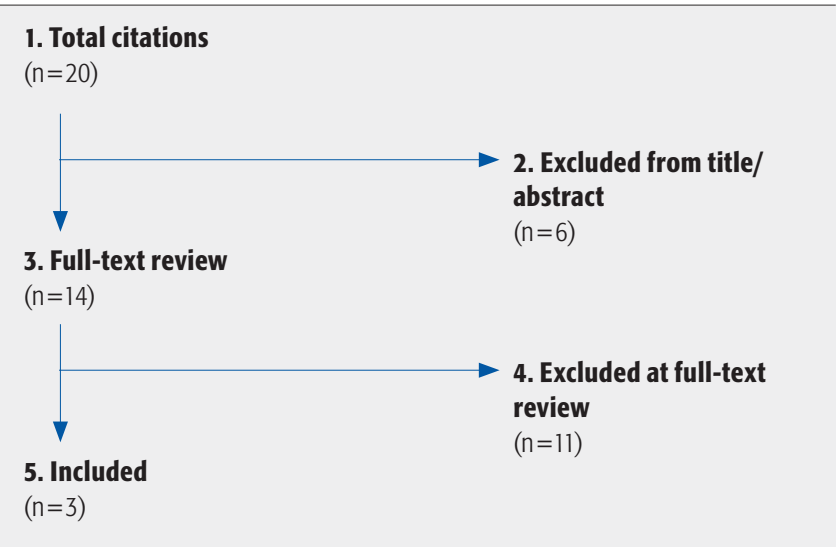

Table 1 Characteristics of included studies.*

\begin{tabular}{|c|c|c|c|c|c|c|c|}
\hline Author & $\begin{array}{l}\text { Study } \\
\text { design }\end{array}$ & Population & Condition and treatment & Intervention & Control & $\begin{array}{l}\text { Follow-up } \\
(\%)\end{array}$ & $\begin{array}{l}\text { Level of } \\
\text { evidence }\end{array}$ \\
\hline 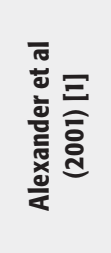 & 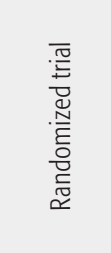 & $\begin{array}{l}\mathrm{N}=40^{\dagger} \\
\text { - Mean age, } \mathrm{y}: 48 \text { (range, 25-74) } \\
-67.5 \% \text { male }\end{array}$ & $\begin{array}{l}\text { Degenerative disc disease or } \\
\text { spondylolisthesis ( } \mathrm{n}=\mathrm{NR}) \\
\text { Instrumented or } \\
\text { noninstrumented posterolateral } \\
\text { lumbar and lumbosacral spinal } \\
\text { fusion with decompression }\end{array}$ & $\begin{array}{l}\text { Decompression } \\
\text { bone plus calcium } \\
\text { sulfate pellets } \\
\text { (OsteoSet }(\AA) \text { on } \\
\text { one side }(n=40)\end{array}$ & $\begin{array}{l}\text { ICBG on } \\
\text { other side } \\
(n=40)\end{array}$ & $\begin{array}{l}1 y \\
(80 \%)\end{array}$ & $\|$ \\
\hline 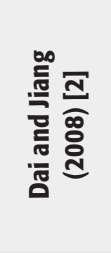 & 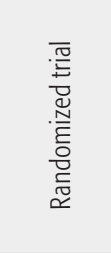 & $\begin{array}{l}\mathrm{N}=62 \\
\text { beta-TCP + local autograft: } \\
- \text { Mean age, y: NR (range, 48-72) } \\
-44 \% \text { male } \\
\text { ICBG: } \\
\text { - Mean age, y: NR (range, 51-73) } \\
-37 \% \text { male }\end{array}$ & $\begin{array}{l}\text { Degenerative lumbar spinal } \\
\text { stenosis } \\
\text { Single-level instrumented } \\
\text { posterolateral spinal fusion with } \\
\text { decompression }\end{array}$ & $\begin{array}{l}\text { beta-TCP plus local } \\
\text { autograft from } \\
\text { decompression } \\
(n=32)\end{array}$ & $\begin{array}{l}\text { ICBG } \\
(n=30)\end{array}$ & $\begin{array}{l}3 y \\
(100 \%)\end{array}$ & $\|$ \\
\hline 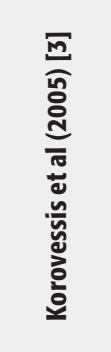 & 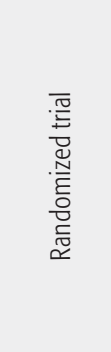 & $\begin{array}{l}\mathrm{N}=60 \\
\text { ICBG: } \\
\text { - Mean age, } \mathrm{y}: 61 \\
\text { - \% male NR } \\
\text { ICBG + HA + local bone + bone marrow: } \\
\text { - Mean age, y: } 64 \\
\text { - \% male: NR } \\
\text { HA + local bone + bone marrow: } \\
\text { - Mean age, y: } 58 \\
\text { - \% male: NR }\end{array}$ & $\begin{array}{l}\text { Symptomatic degenerative } \\
\text { lumbar spine stenosis with } \\
\text { instability } \\
\text { Instrumental posterolateral } \\
\text { lumbar and lumbosacral fusion }\end{array}$ & $\begin{array}{l}\text { 1. ICBG left side } \\
\text { plus HA mixed with } \\
\text { local bone and } \\
\text { bone marrow of } \\
\text { right }(n=20) \\
\text { 2. HA mixed with } \\
\text { local bone and } \\
\text { bone marrow on } \\
\text { both sides }(n=20)\end{array}$ & $\begin{array}{l}\text { Bilateral } \\
\text { ICBG } \\
(n=20)\end{array}$ & $\begin{array}{l}\text { Up to } 4 \text { y } \\
\text { (95\% at } 3 \text { y) }\end{array}$ & $\|$ \\
\hline
\end{tabular}

${ }^{*}$ NR indicates not reported; ICBG, iliac crest bone graft; TCP, tricalcium phosphate; and HA, hydroxyapatite.

$\dagger$ Each patient received an intervention and control treatment and served as his own control.

Table 2 Complications.*

\begin{tabular}{|c|c|c|}
\hline Author & Treatment groups & Complications \\
\hline Alexander et al (2001) [1] & $\begin{array}{l}\text { A. Decompression bone and calcium sulfate pellets on one side } \\
\text { B. ICBG on other side }\end{array}$ & Not reported \\
\hline Dai and Jiang (2008) [2] & $\begin{array}{l}\text { A. beta-TCP plus local autograft from decompression } \\
\text { B. ICBG plus decompression }\end{array}$ & $\begin{array}{l}A=\text { none } \\
B=\text { none }\end{array}$ \\
\hline Korovessis et al (2005) [3] & $\begin{array}{l}\text { A. HA plus local bone and BMA on one side, ICBG on other side } \\
\text { B. HA plus local bone and BMA bilateral } \\
\text { C. ICBG bilateral }\end{array}$ & $\begin{array}{l}A=\text { Deep infection }(n=1) \text {; superficial infection }(n=1) \\
B=\text { Deep infection }(n=1) \\
C=\text { Deep hematoma }(n=1) \text {; screw breakage }(n=1)\end{array}$ \\
\hline
\end{tabular}

* ICBG indicates iliac crest bone graft; TCP, tricalcium phosphate; HA, hydroxyapatite; and BMA, bone marrow aspirate. 
Fig 2 Fusion rates of bone extender plus local bone graft vs iliac bone crest graft.

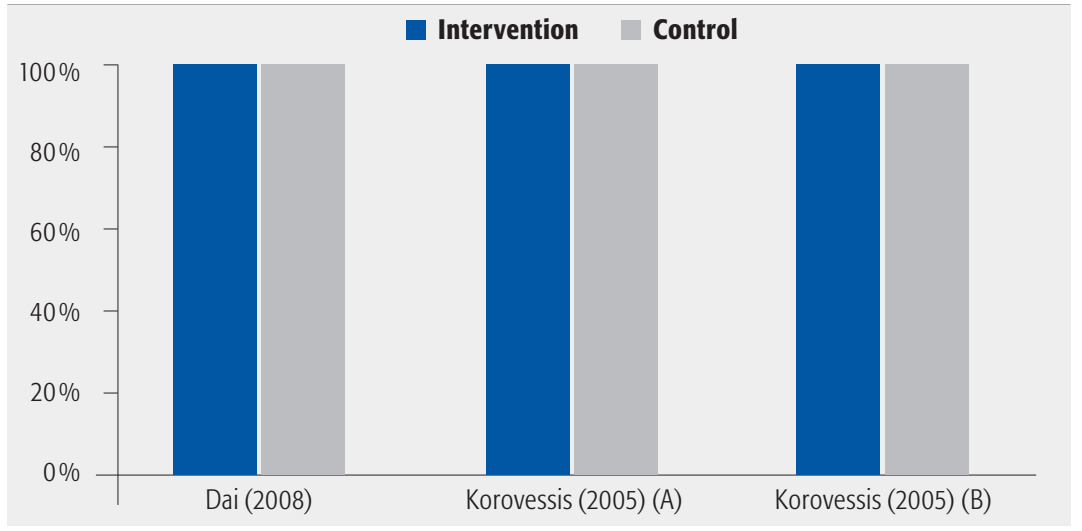

Dai and Jiang [2]: intervention indicates $\beta$-tricalcium phosphate plus local autograft; and control, iliac crest bone graft.

Korovessis et al [3]: intervention A indicates hydroxyapatite with bone marrow aspirate plus local bone on one side, iliac crest bone graft on the other; intervention $\mathrm{B}$, hydroxyapatite with bone marrow aspirate plus local bone on both sides; and control, iliac crest bone graft on both sides.

Fig 3 Functional and QoL outcomes (A) mean score improvement at follow-up (F/U) vs baseline; (B) mean percentage improvement at follow-up vs baseline. Error bars represent 95\% confidence intervals.

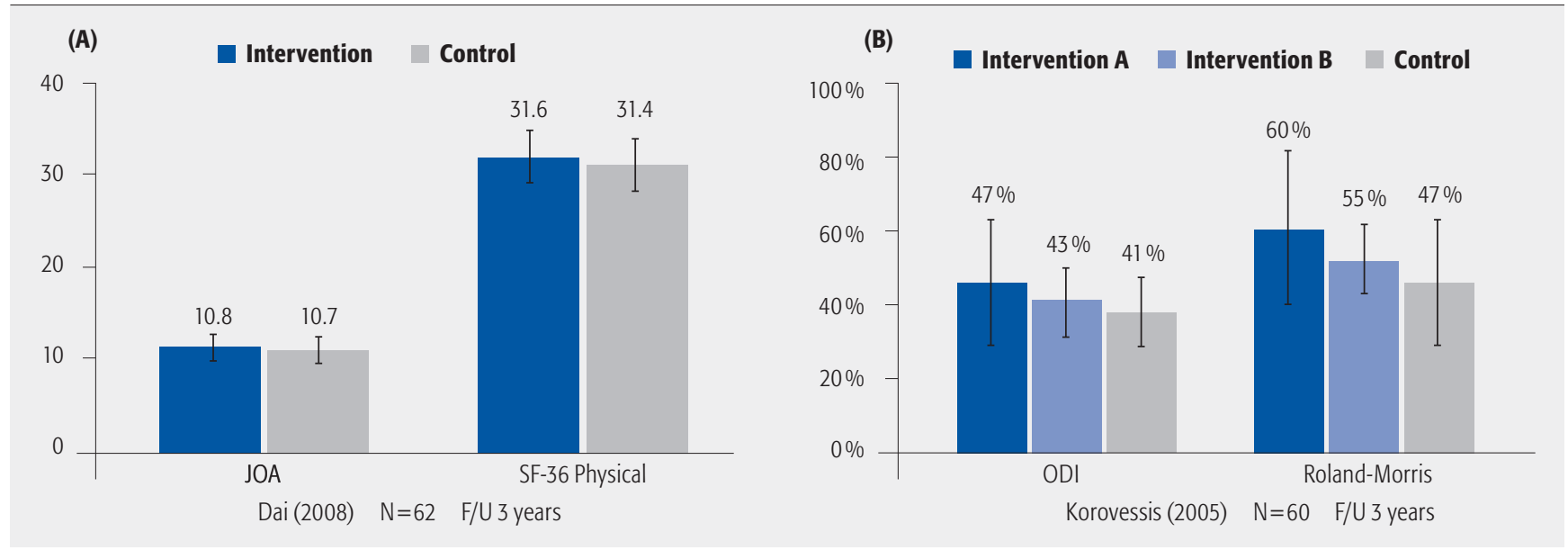

Dai and Jiang [2]: intervention indicates $\beta$-tricalcium phosphate plus local autograft; and control, iliac crest bone graft.

Korovessis et al [3]: intervention A indicates hydroxyapatite with bone marrow aspirate plus local bone on one side, iliac crest bone graft on the other; intervention B, hydroxyapatite with bone marrow aspirate plus local bone on both sides; and control, iliac crest bone graft on both sides.

Fig 4 AP $x$-ray reveals excellent bone growth and stable intertransverse fusion at the $L 4 / 5$ level.

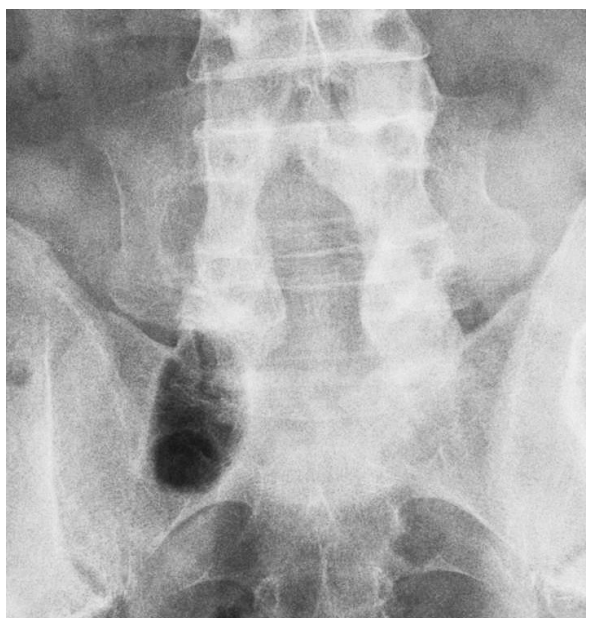

Fig 5 Lateral $x$-ray reveals excellent bone mass

in the posterolateral space between $L 4 / 5$.

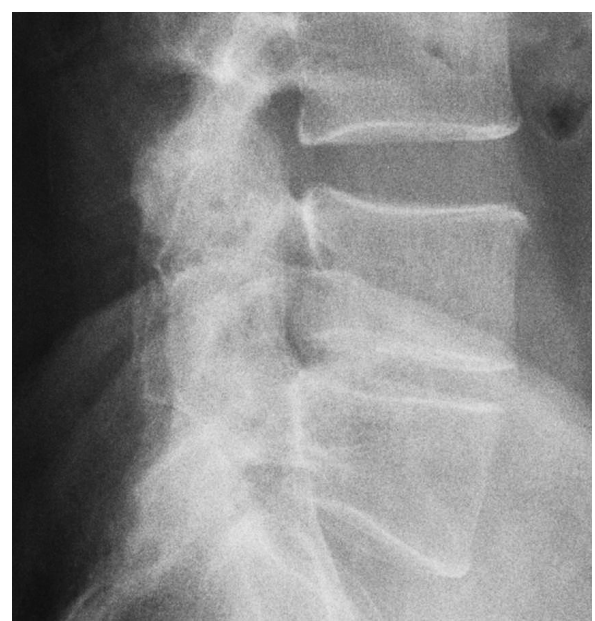




\section{EVIDENCE SUMMARY}

\begin{tabular}{|c|c|c|c|c|c|}
\hline \multicolumn{6}{|l|}{ Fusion } \\
\hline Outcomes & \multicolumn{4}{|c|}{ Strength of evidence ${ }^{*}$} & \multirow{2}{*}{$\begin{array}{l}\text { Conclusions/Comments } \\
\text { Fusion rates were high and similar across treatment groups }\end{array}$} \\
\hline 1. Rate of fusion & Very low & Low & Moderate & High & \\
\hline \multicolumn{6}{|c|}{ Functional status and QoL } \\
\hline Outcomes & \multicolumn{4}{|c|}{ Strength of evidence ${ }^{*}$} & Conclusions/Comments \\
\hline 1. Functional scores & \multicolumn{2}{|l|}{ Very low } & \multicolumn{2}{|l|}{ Moderate } & $\begin{array}{l}\text { Functional status scores improved after fusion and did not differ } \\
\text { significantly between treatment groups }\end{array}$ \\
\hline 2. QoL scores & Very low & Low & Moderate & High & $\begin{array}{l}\text { QoL scores improved after fusion and did not differ significantly } \\
\text { between treatment groups }\end{array}$ \\
\hline \multicolumn{6}{|l|}{ Complications } \\
\hline Outcomes & \multicolumn{2}{|c|}{ Strength of evidence ${ }^{*}$} & & & \multirow{2}{*}{$\begin{array}{l}\text { Conclusions/Comments } \\
\text { Complications were rare, but one study reported a } 5.3 \% \text { rate of } \\
\text { deep infection in patients treated with local bone plus extender }\end{array}$} \\
\hline 1. Complications & Very low & Low & Moderate & High & \\
\hline
\end{tabular}

\section{CLINICAL GUIDELINES}

The American Association of Neurological Surgeons/Congress of Neurological Surgeons has released one guideline related to use of bone graft extenders and substitutes [4]. This guideline does not offer recommendations related to the use of local bone plus extender.

\section{ILLUSTRATIVE CASE}

A 45-year-old man was admitted for decompression and fusion for lateral recess stenosis and instability. The bone harvested locally from the spinal decompression was combined with demineralized bone matrix for a posterolateral fusion. The results are seen in the AP and lateral x-ray 6 years postoperatively. Note the mature bone in the posterolateral gutter bilaterally at the L4/5 level (Figs 4-5).

\section{DISCUSSION}

- In the three comparative studies that evaluated local bone graft plus bone extender for posterolateral lumbar fusion, fusion rates, functional outcomes, and QoL outcomes were similar in patients treated with the extender or with ICBG. There were two deep infections $(5.3 \%)$ in one study among patients receiving local bone graft plus extender.

- This systematic review is limited by the following:

- Significant heterogeneity among studies with respect to variation in the type of test materials used, procedural details, and methods of comparing test material with ICBG.

- Discordant functional or lack of functional and QoL outcomes.

- Varying definitions of fusion and disparate ways of assessing.

- The use of locally harvested bone from the spine combined with extenders or extenders plus bone marrow aspirate has been shown to be equivalent to that of ICBG but without associated morbidity. 


\section{REFERENCES}

1. Alexander DI, Manson NA, Mitchell MJ (2001) Efficacy of calcium sulfate plus decompression bone in lumbar and lumbosacral spinal fusion: preliminary results in 40 patients. Can J Surg; 44(4):262-266.

2. Dai LY, Jiang LS (2008) Single-level instrumented posterolateral fusion of lumbar spine with beta-tricalcium phosphate versus autograft: a prospective, randomized study with 3-year follow-up. Spine (Phila Pa 1976); 33(12):1299-1304.

3. Korovessis $\mathbf{P}$, Koureas $\mathbf{G}$, Zacharatos $\mathbf{S}$, et al (2005) Correlative radiological, self-assessment and clinical analysis of evolution in instrumented dorsal and lateral fusion for degenerative lumbar spine disease: autograft versus coralline hydroxyapatite. Eur Spine J; 14(7):630-638.

4. Resnick DK, Choudhri TF, Dailey AT, et al (2005) Guidelines for the performance of fusion procedures for degenerative disease of the lumbar spine. Part 16: bone graft extenders and substitutes. J Neurosurg Spine; 2(6):733-736.

5. Sasso RC, LeHuec JC, Shaffrey C (2005) Iliac crest bone graft donor site pain after anterior lumbar interbody fusion: a prospective patient satisfaction outcome assessment. J Spinal Disord Tech; 18:S77-81.

6. Glassman SD, Howard J, Dimar J et al (2010) Complications with rhBMP-2 in Posterolateral Spine Fusion: a consecutive series of one thousand thirty-seven cases. Spine (Phila Pa 1976); Sept 10[Epub ahead of print].

\section{EDITORIAL STAFF PERSPECTIVE}

This systematic review on the subject of bone graft extenders compares fusion results after pairing inorganic material with local bone graft in contrast to the gold standard achievable with autogenous iliac crest allograft.

The reviewers criticized McGuire and colleagues' use of the nonspecific term of bone graft extenders rather than differentiating tricalcium phosphate from calcium sulfate and other synthetic materials, such as ceramics. The question if any of these devices are superior to one another has not been answered and the ideal composition of a graft/extender mix has also been more subject to conjecture than science. The reviewers did point out that the biological activation of the bone graft extender in the studies mentioned differed. One major study actually used bone marrow aspirate rather than local bone graft, thus creating yet another subcategory of bone graft supplementation.

Another major problem is the lack of clear diagnostic categories in the populations used. For example, any study in which patients with lumbar spine conditions that involve stenosis decompression surgery will likely lead to much better outcomes than fusion surgery done for back pain without neural encroachment and/or instability. To associate the expected postoperative improvement of the stenosis patients recruited for all three studies mainly with the use of bone extenders would be a clearly flawed proposition.

Another point worth considering is the popular intrinsic "self-control" study design of "left" versus "right" in fusion studies. While the study design is simple, as the consolidation of a control side may improve healing chances of the experimental side and vice versa. Also, systemic complications, such as infection, would likely affect both sides and lead to failure attributable to both, when in fact it may have been just one of the study groups that lead to the complication.

A final but important note is that of the business aspect of bone graft extenders. Despite absence of any improvement of bone healing of graft extenders compared with conventional bone graft techniques, the business with osteobiologics including bone graft extenders is booming. The potential for conflict of interest in single-vendor industry-sponsored studies and an increased prevalence to report positive results has been reported and should be considered by an inquisitive surgeon before changing practice patterns [1]. It seems reasonable to remain critical of excessive claims of bone healing associated with any of these synthetic and intrinsically biologically inert materials at this point in time.

Lynch JR, Cunningham MR, Warme WJ, et al (2007) Commercially funded and United States-based research is more likely to be published: good-quality studies with negative outcomes are not. J Bone Joint Surg Am; 89:(5)1010-1018. 